\title{
Pathological crosstalk in vitro between T lymphocytes and lesional keratinocytes in psoriasis: necessity of direct cell-to-cell contact
}

\author{
Guillaume Martin 1,2,3, Simon Guérard ${ }^{1,2,3}$, Marie-Michèle Rosa Fortin ${ }^{1,2,3}$, Daniel Rusu ${ }^{2,4}$, Jacques Soucy ${ }^{5}$, \\ Patrice E Poubelle ${ }^{2,4}$ and Roxane Pouliot ${ }^{1,3}$
}

\begin{abstract}
Psoriasis, a chronic autoimmune-related skin disease, involves both immune and non-immune cells like T cells and keratinocytes. This study investigates the regulatory role of T cells-keratinocyte interactions during psoriasis on immune factors production. Cytokines and chemokines were evaluated by multiplex and ELISA assays in an in vitro model of co-culture of keratinocytes with T lymphocytes. Keratinocytes were from psoriatic skin lesions or healthy skin. T lymphocytes were from healthy volunteers. Psoriatic keratinocytes (PKs) alone generated concentrations of tumor necrosis factor (TNF)- $\alpha$, interleukin (IL)-6, granulocyte-macrophage colony-stimulating factor (GM-CSF), IL-1 $\beta$, IL-8, monocyte chemotactic protein (MCP)-1, interferon- $\gamma$-induced protein $10 \mathrm{kDa}$ (IP-10) and vascular endothelial growth factor (VEGF) higher than those produced by healthy keratinocytes (HKs). In contrast, IL-1 $\alpha$ and IL-Ra production was reduced in PKs. Normal T cells, which had no effect on HKs, increased the production of TNF- $\alpha$, IL-6, GM-CSF, IL-8, MCP-1 and IP-10 by PKs, but did not influence PK production of IL-1 $\beta$, IL- $1 \alpha$, IL-Ra and VEGF. The most striking effects were obtained with PK- and IL-2-stimulated T lymphocytes: most of the above cytokines and chemokines were greatly upregulated, except IL-1 $\beta$ and VEGF that were decreased or unchanged, respectively. In addition, fractalkine was overproduced in this latter condition only. Our results indicate (1) a functional interaction between keratinocytes and T lymphocytes that requires a direct cellular contact, and (2) a reciprocal influence that depends on cytokine and chemokine types. In conclusion, lesional keratinocytes from psoriasis vulgaris alter functions of normal T lymphocytes that conversely modulate these keratinocytes.
\end{abstract}

Laboratory Investigation (2012) 92, 1058-1070; doi:10.1038/labinvest.2012.69; published online 23 April 2012

KEYWORDS: chemokines; cytokines; fractalkine; inflammation

Psoriasis vulgaris is a chronic skin disease affecting approximately $2 \%$ of the worldwide population. ${ }^{1}$ In the past, the disease was thought to originate from a primary disorder in epidermal keratinocytes that led to their hyperproliferation

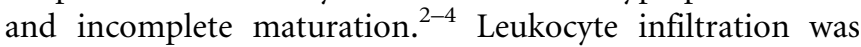
only viewed as a secondary event. However, the implication of the immune system as an initiator of the symptoms in psoriasis was slowly recognized in the 1980s when new evidences, such as successful treatment with cyclosporin A, a T-cell immunosuppressant, demonstrated the necessity of immune cells in the development of lesions. ${ }^{5}$ The role of immune cells has elegantly been confirmed in SCID mice engrafted with non-lesional skin from patients with psoriasis.
These non-lesional full-thickness skin were converted into psoriatic plaques when mice were injected in the dermis with IL-2-preactivated T lymphocytes from the same patients. ${ }^{6}$ Psoriasis is now recognized as one of the most common immune-related disease. ${ }^{1,2,7}$ Scientific evidences that support a dysregulated immune system in psoriasis have progressively accumulated, such as the presence of augmented concentrations of $\mathrm{T}$ and dendritic cells, as well as of clonal T lymphocytes in skin lesions. ${ }^{8-10}$ The clinical benefit of treating psoriatic patients with monoclonal anti-CD4 antibodies, with a chimeric IgG-receptor fragment CTLA-4 fusion protein or with the selective lymphocyte toxin DAB389IL-2, strengthened the implication of $\mathrm{T}$ lymphocytes in psoriasis. ${ }^{10-13}$

\footnotetext{
${ }^{1}$ Laboratoire d'Organogénèse Expérimentale (LOEX), Québec, QC, Canada; ${ }^{2}$ Centre de Recherche en Rhumatologie et Immunologie (CRRI), Centre de Recherche du CHUQ, Québec, QC, Canada; ${ }^{3}$ Faculté de Pharmacie, Québec, QC, Canada; ${ }^{4}$ Département de Médecine, Université Laval, Québec, QC, Canada and ${ }^{5}$ Département de Dermatologie, Hôpital de l'Enfant-Jésus, Québec, QC, Canada

Correspondence: Professor PE Poubelle, MD, DSc, Département de Médecine, Université Laval-CRRI, Centre de Recherche du CHUQ, 2705, Boul Laurier, \#T1-49, Québec, QC, G1V 4G2 Canada.

E-mail: patrice.poubelle@crchul.ulaval.ca

Received 6 November 2011; revised 11 March 2012; accepted 13 March 2012
} 
Interestingly, dermal dendritic cells from psoriatic skin lesions have been shown to drive greatly the cytokine production towards type 1 helper T lymphocyte (Th1) and Th17 cytokines. ${ }^{14,15}$ However, Th17 cells are mainly present in the dermis of psoriasis skin lesions. ${ }^{16} \mathrm{~T}$ lymphocytes from psoriasis lesions have been shown to produce type 1 cytokines like interferon (IFN)- $\gamma$, IL-2 and TNF- $\alpha .{ }^{17}$ In addition, TNF- $\alpha$-dependent proliferation of resident $\mathrm{T}$ lymphocytes in prepsoriatic lesions is required to lead to skin lesions. ${ }^{18}$ Moreover, lesional $\mathrm{T}$ lymphocytes have the capacity to promote the proliferation of non-involved keratinocytes from psoriasis skin, but not of keratinocytes from the normal skin. ${ }^{19-21}$ These data, which suggested the necessity of altered $\mathrm{T}$ lymphocytes and keratinocytes to lead to psoriasis lesions, have been corroborated by studies with $\mathrm{K} 5$.Stat3C transgenic mice whose keratinocytes constitutively expressed active Stat3, required the presence of activated $\mathrm{T}$ cells in their skin to develop psoriasis lesions. ${ }^{22}$ A corollary of these complex interactions between psoriatic keratinocytes (PKs) and lesional T lymphocytes is the massive production of factors like cytokines and chemokines responsible for cellular proliferation and activation, attraction of circulating leukocytes into the skin, neo-angiogenesis and inflammation. ${ }^{1,23,24}$ However, if psoriasis is not definitively considered as a real autoimmune disease, it is undoubtedly an autoimmune-related disease where immunocytes ( $\mathrm{T}$ lymphocytes, dendritic cells, macrophages, neutrophils) and keratinocytes are the major players. ${ }^{1,23}$ Certain cytokines and chemokines are uniquely produced by keratinocytes or $\mathrm{T}$ lymphocytes, and others are generated by both cell types. In addition, in vitro studies reported that normal or lesional $\mathrm{T}$ lymphocytes have to be preactivated to produce cytokines in response to PKs. ${ }^{6,25}$ Considering the vast network of cytokines and chemokines presently known, we hypothesized that (1) the required condition of preactivated $\mathrm{T}$ lymphocytes to generate such factors is restricted to certain products only, and (2) the interaction between keratinocytes and T lymphocytes is not restricted to lesional cells. To answer these issues in terms of psoriasis pathogenesis, we used part of a new in vitro psoriatic skin model ${ }^{26}$ and the versatile multiplex assay to investigate the possible abnormal crosstalk between PKs and normal pure $\mathrm{T}$ lymphocytes with or without the presence of IL-2.

\section{MATERIALS AND METHODS} Isolation of Keratinocytes

The institutional review board of the Universite Laval approved the study, and volunteers signed a consent form in accordance with the Declaration of Helsinki. Skin biopsies were obtained from three patients with chronic plaques of psoriasis vulgaris and from two healthy subjects that required reductive breast surgery. Patients with psoriasis were three women aged of 35, 46 and 65 years. Skin lesions corresponded to 40,15 and $15 \%$ of body surface, respectively. Two patients received oral methotrexate, and one patient was treated with topical creams. Tissues were harvested, as described previously. ${ }^{27}$ Briefly, skin tissues were treated with thermolysin that digests the dermoepidermal junction to separate efficiently the dermis from the epidermis. The epidermis was then treated with trypsin to obtain a cell suspension containing all the basal layer of keratinocytes. These extracted cells were frozen at $-150{ }^{\circ} \mathrm{C}$ for further use from passages 0 to 3 .

\section{Preparation of T Lymphocytes}

All steps of preparation using human venous blood from healthy donors were performed under sterile conditions at room temperature. Anticoagulated blood was layered over Ficoll-Paque cushions and centrifuged at $400 \mathrm{~g}$ for $20 \mathrm{~min}$, according to our previous report. ${ }^{28}$ The mononuclear leukocyte fraction was collected at the interface, and was washed and resuspended in $\alpha$-MEM $+10 \%$ FBS. Mononuclear leukocytes $\left(5 \times 10^{6}\right.$ cells per $\left.\mathrm{ml}\right)$ were then subjected to adherence on plastic Petri dishes. To remove completely monocytes from mononuclear leukocytes, three successive periods of adherence $\left(1 \mathrm{~h}, 2 \mathrm{~h}\right.$ and overnight, $\left.37^{\circ} \mathrm{C}\right)$ were performed before collecting non-adherent cells for the experiments. Differential cell counts of leukocytes were carried out by cytofluorometry (flow cytometer EPICS-XL; Beckman Coulter, Miami, FL, USA) using forward-angle and right-angle light scatter criteria and specific FITC-conjugated monoclonal anti-CD3 antibody (pan-T lymphocytes), and by nonspecific esterase staining (monocytes). The non-adherent fraction represented 98-99\% $\mathrm{CD} 3+$ cells, and monocyte contamination was $<0.1 \%$.

\section{Culture of Keratinocytes and Lymphocytes}

Cells were resuspended and cultured in Dulbecco/Vogt modified Eagle's minimal essential medium (DMEM) with Ham's F12 (ratio DMEM/F12:3/1) supplemented with 5\% HyClone FetalClone II (Fisher Scientific, part of Thermo Fisher Scientific, Ottawa, ON, Canada), $5 \mu \mathrm{g} / \mathrm{ml}$ insulin (Sigma-Aldrich Canada, Oakville, ON, Canada), $0.4 \mu \mathrm{g} / \mathrm{ml}$ hydrocortisone (Cedarlane, Burlington, ON, Canada), $10^{-10} \mathrm{M}$ cholera toxin (ICN Biochemicals, Montréal, QC, Canada), $10 \mathrm{ng} / \mathrm{ml}$ human epidermal growth factor (Austral Biologicals, San Ramon, CA, USA), $100 \mathrm{UI} / \mathrm{ml}$ penicillin (Sigma-Aldrich) and $25 \mu \mathrm{g} / \mathrm{ml}$ gentamicin (Schering Canada, Pointe-Claire, QC, Canada). Keratinocytes (passage 3) were seeded in the culture medium at a density of $1.3 \times 10^{4}$ cells per $\mathrm{cm}^{2}$ on a feeder layer of irradiated 3T3 mouse fibroblasts $\left(2 \times 10^{4}\right.$ cells per $\left.\mathrm{cm}^{2}\right)$, as reported previously, ${ }^{26}$ with $2 \times 10^{6}$ $\mathrm{T}$ lymphocytes in 6-well culture plates $(2 \mathrm{ml}$ per well). Healthy keratinocytes (HKs) or PKs, and T lymphocytes were also evaluated alone, and with $30 \mathrm{U} / \mathrm{ml}$ of recombinant human IL-2 (R\&D Systems, Burlington, ON, Canada). Cells were cultured for 13 days at $37^{\circ} \mathrm{C}$ in an $8 \% \mathrm{CO}_{2}$ air atmosphere and $1 \mathrm{ml}$ medium per well was removed to add fresh medium three times a week. In these experimental conditions, we previously showed that PKs were significantly more efficient than HKs to enhance T lymphocyte survival. ${ }^{29}$ In experiments 
devoted to the role of direct contact between keratinocytes and $\mathrm{T}$ lymphocytes, culture conditions of cells were similar as above, except that $\mathrm{T}$ lymphocytes were placed on top of BD Falcon cell culture inserts for 6-well plates $(0.4 \mu \mathrm{m}$, translucent PET (polyethylene terephthalate) membrane; BD Biosciences, Mississauga, ON, Canada), and wells were filled up with $4.2 \mathrm{ml}$ culture medium. Supernatants were collected at day 13 and frozen at $-80^{\circ} \mathrm{C}$ until assayed for cytokines/chemokines.

\section{Confocal Microscopy}

To assess the contact zones of lymphocytes adherent to keratinocytes, confluent PKs were washed twice with HBSS and stained with $2 \mu \mathrm{M}$ CMTMR ( $30 \mathrm{~min}, 37^{\circ} \mathrm{C}$ ). Lymphocytes $\left(10 \times 10^{6} / \mathrm{ml}\right)$, previously stained with $4 \mu \mathrm{M}$ PKH-67 green fluorescent cell linker ( $2 \mathrm{~min}$, room temperature), were added to $\mathrm{PK}$ in culture with $30 \mathrm{U} / \mathrm{ml} \mathrm{IL}-2$ and incubated for $120 \mathrm{~min}$ at $37^{\circ} \mathrm{C}$ in a $\mathrm{CO}_{2}$ incubator. Cells were then washed three times (5 min in PBS) and observed with an Olympus Fluoview 300 confocal microscope using Argon-ion $(488 \mathrm{~nm})$ and Helium-neon $(543 \mathrm{~nm}$ ) lasers. Then, 117 slices of $0.3 \mu \mathrm{m}$ were scanned (magnification, $\times 600$, plan Apo, NA 1.4 with a Kalman filter 3 ) to reconstitute $z$ plans.

\section{Evaluation of Cytokines/Chemokines}

Measurement of cytokines and chemokines was initially performed by using a multiplex assay (simultaneous analysis of IL-1 $\beta$, IL-4, IL-6, IL-8, IL-10, IL-12p70, IL-12p40, IL-15, IL-17, MCP-1, granulocyte-macrophage colony-stimulating factor (GM-CSF), FGF-2, eotaxin, sCD40L, fractalkine, sIL$2 \mathrm{R} \alpha$, TNF- $\alpha$, IFN- $\gamma$, interferon- $\gamma$-induced protein $10 \mathrm{kDa}$ (IP-10) and vascular endothelial growth factor (VEGF)) and completed by ELISAs for certain analytes (IL-1Ra, IL- $1 \alpha$, IL-8, MCP-1, IFN- $\gamma$, IP-10, IL-6, fractalkine and VEGF). The multiplex assay (Human Cytokine/Chemokine Panel) that used the Luminex xMAP technology (Luminex Molecular Diagnostics, Toronto, ON, Canada) was carried out in 96well plates according to Millipore's protocol (Millipore, Billerica, MA, USA). Analysis was made using the LiquiChip Analyzer Software (Qiagen, Mississauga, ON, Canada). IL-Ra was measured using an ELISA kit purchased from R\&D Systems (Minneapolis, MN, USA). The IL-1Ra detection limit was $39 \mathrm{pg} / \mathrm{ml}$, with no crossreactivities with IL- $1 \beta$, IL- $1 \alpha$ and sIL-1RII. IL- $1 \alpha$ was measured by an ELISA (detection limit of $3.0 \mathrm{pg} / \mathrm{ml}$ ) from Cayman Chemical (Ann Arbor, MI, USA). IL-8 was quantified by using an ELISA kit (detection limit of $12.5 \mathrm{pg} / \mathrm{ml}$ ) from Biosource International (Camarillo, CA, USA). MCP-1, IFN- $\gamma$ and IL- 6 were evaluated by ELISA kits purchased from eBioscience (San Diego, CA, USA) with detection limits of 7, 4 and $2 \mathrm{pg} / \mathrm{ml}$, respectively. Fractalkine and VEGF were measured with ELISA kits (detection limit of 39 and $30 \mathrm{pg} / \mathrm{ml}$, respectively) from R\&D Systems. All measurements were performed in duplicate.
Table 1 Production of cytokines and chemokines by healthy and psoriatic keratinocytes

\begin{tabular}{lccc}
\hline Cytokines/chemokines* & Healthy $\mathrm{K}$ & Psoriatic K & PK/HK \\
\hline TNF- $\alpha$ & $8.2 \pm 2.3$ & $54.6 \pm 18.6^{\mathrm{a}}$ & 6.7 \\
IFN- $\gamma$ & $\mathrm{ND}$ & $\mathrm{ND}$ & - \\
IL-6 & $7.7 \pm 2.8$ & $48.2 \pm 15.3^{\mathrm{b}}$ & 6.2 \\
GM-CSF & $32.3 \pm 5.6$ & $293.3 \pm 93.0^{\mathrm{c}}$ & 9.2 \\
IL-15 & $8.1 \pm 2.7$ & $10.4 \pm 1.2$ & $\mathrm{NC}$ \\
IL-17 & $\mathrm{ND}$ & $\mathrm{ND}$ & - \\
SIL-2R $\alpha$ & $\mathrm{ND}$ & $\mathrm{ND}$ & - \\
IL-1 $\alpha$ & $280.7 \pm 43.9$ & $150.8 \pm 46.9^{\mathrm{d}}$ & 0.5 \\
IL-1 $\beta$ & $18.4 \pm 2.4$ & $142.4 \pm 43.4^{\mathrm{e}}$ & 7.7 \\
IL-1Ra & $134782 \pm 12229$ & $29035 \pm 12081^{\mathrm{f}}$ & 0.2 \\
IL-1Ra/IL-1 & 451 & 99 & - \\
IL-8 & $962 \pm 200$ & $3728 \pm 1093^{9}$ & 3.9 \\
MCP-1 & $57.7 \pm 12.5$ & $152.0 \pm 38.0^{\mathrm{h}}$ & 2.6 \\
IP-10 & $185.5 \pm 52.5$ & $1880 \pm 421^{\mathrm{i}}$ & 10.1 \\
Fractalkine & $53.0 \pm 16.7$ & $95.7 \pm 21.3$ & $\mathrm{NC}$ \\
& & &
\end{tabular}

ND, non-detectable; NC, no change.

Keratinocytes (K) were cultured in DMEM/F12+5\% FetalClone II to evaluate the accumulation of cytokines/chemokines in supernatants after 13 days. The analytes TNF- $\alpha$, IFN- $\gamma$, IP-10, IL-6, MCP-1, IL-1 $\beta$, GM-CSF, IL-15, sIL-2R $\alpha$ and fractalkine were evaluated by using the Luminex XMAP technology, and IL- $1 \alpha$, IL-1Ra and IL- 8 were measured by using EIA kits. In the ratio IL-1Ra/IL-1, IL-1 represents the sum of IL-1 $\alpha+\mathrm{IL}-1 \beta$.

* Results are expressed as means \pm s.e.m. in $\mathrm{pg} / \mathrm{ml}$ per million of healthy (HKs, $n=8$ ) and psoriatic keratinocytes (PKs, $n=9$ ).

Statistical analysis (two-tailed $t$-test, HKs vs PKs).

${ }^{\mathrm{a}} \mathrm{P}=0.0025$.

${ }^{\mathrm{b}} P=0.0269$.

${ }^{c} P=0.0188$.

$\mathrm{d}_{P=0.0003 .}$

$\mathrm{e}_{P}=0.0330$.

${ }^{\mathrm{f}} P<0.0001$.

$\mathrm{g}_{P}=0.0446$

$\mathrm{h}_{P=0.0388 .}$

${ }^{\mathrm{i}} P=0.0045$.

\section{Statistical Analysis}

Results are expressed as means \pm s.e.m. Analyses were performed with Prism 4 (GraphPad Software, San Diego, CA, USA). Comparisons between two groups were analyzed by paired or unpaired $t$-tests. Significance was set at $P<0.05$.

\section{RESULTS \\ PKs Cooperate with Normal T Cells to Overproduce Pro-Inflammatory Cytokines}

PKs have an altered production of various cytokines. ${ }^{1,30}$ To evaluate the basal output of cytokines by keratinocytes, they were first cultured as monolayers without the addition of lymphocytes. Interestingly, the production of TNF- $\alpha$, IL- 6 and GM-CSF by PKs was significantly more elevated than 

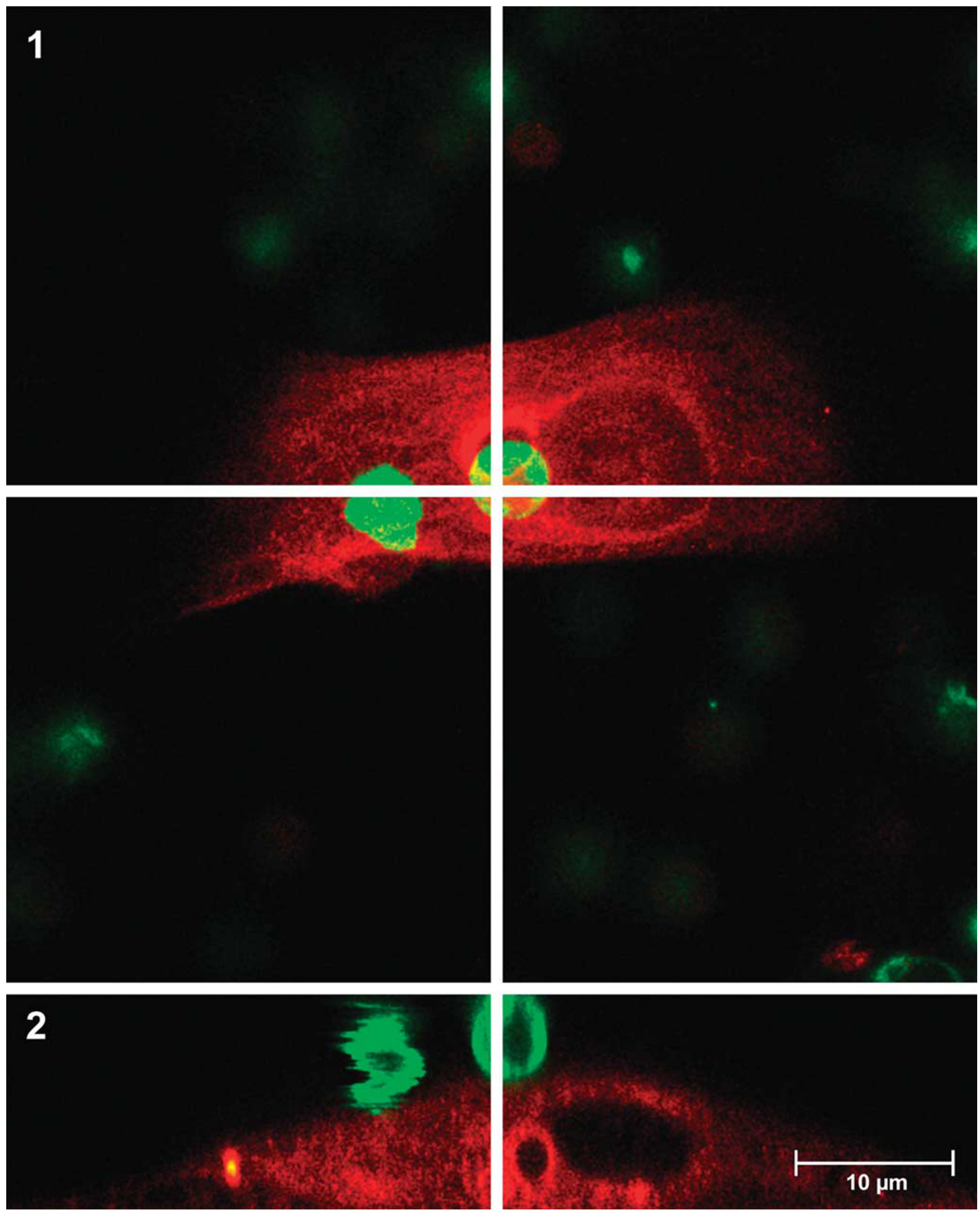

Figure 1 Visualization of cellular contact between psoriatic keratinocytes and normal T lymphocytes. Confluent psoriatic keratinocytes (PKs) previously stained with CMTMR were incubated for $120 \mathrm{~min}$ at $37^{\circ} \mathrm{C}$ in a $\mathrm{CO}_{2}$ incubator with $30 \mathrm{U} / \mathrm{ml}$ interleukin (IL)-2 and lymphocytes prelabeled with PKH-67 Green Fluorescent Cell Linker ( 2 min at room temperature). Cells were then washed and visualized by confocal microscopy (magnification $\times 600$, plan Apo, NA 1.4 with a Kalman filter 3). Then, 117 slices of $0.3 \mu \mathrm{m}$ were scanned to reconstitute $z$ plans. (1) Stacking view and (2) $z$ plan of $X$ axis. 
that of HKs. PKs generated 6.7, 6.2 and 9.2 times more of these cytokines, respectively, than their healthy counterparts. Both types of keratinocytes produce no IFN- $\gamma$, no IL-17, no sIL-2R $\alpha$, and their IL-15 generation was similar (Table 1). The other cytokines studied, IL-4, $-10,-12 \mathrm{p} 70,-12 \mathrm{p} 40$, FGF-2 and sCD40L, were undetectable. The addition of IL-2, a powerful stimulator of T cells, to HKs or PKs did not alter their production of cytokines and chemokines (data not shown), indicating that $\mathrm{HKs}$ and PKs had no specific receptors expressed at their surface to respond to IL-2.

As $\mathrm{T}$ lymphocytes adhere to keratinocytes, ${ }^{31}$ we first verified that $\mathrm{T}$ lymphocytes added to keratinocytes generated through our in vitro psoriatic skin model can efficiently bind to these keratinocytes. After $2 \mathrm{~h}$ of co-incubation, normal $\mathrm{T}$ lymphocytes greatly adhere to PKs and the lymphocyte membrane in contact with keratinocytes showed local concentration of the fluorescent dye PKH67 (Figure 1). T lymphocytes incubated with IL-2 generated low amounts of TNF- $\alpha$, IFN- $\gamma$, IL- 6 and GM-CSF (Table 2). The addition of $\mathrm{T}$ lymphocytes to HK did not modify their cytokine production (Figures 2a, c and e). In contrast, PKs cultured with $\mathrm{T}$ lymphocytes, compared with PKs cultured alone, increased their production of TNF- $\alpha$, IL- 6 and GM-CSF by 2.3-, 2- and 3.4-fold, respectively (Table 3 ). PKs with T lymphocytes, in comparison to HKs with T lymphocytes, produced 10.9, 9.4 and 22.9 times more TNF- $\alpha$, IL- 6 and GM-CSF, respectively (Table 3). IFN- $\gamma$ remained undetectable.

The most striking effects on both keratinocyte types were obtained with the addition of IL-2-activated T lymphocytes. PKs cultured with IL-2-activated $\mathrm{T}$ lymphocytes generated TNF- $\alpha$, IL- 6 and GM-CSF 6.7, 5.2 and 6.3 times more than PK alone, respectively (Figure 2). Interestingly, HKs were also affected by the presence of IL-2-activated T lymphocytes. Comparatively with HKs alone, they increased their production of TNF- $\alpha$, IL- 6 and GM-CSF by a fold of 5, 15 and 21.5 , respectively (Figure 2). However, their basal output of these cytokines was much more lower than those of PKs (Table 1). The amounts of IFN- $\gamma$, a cytokine generated by T lymphocytes only (Tables 1 and 2), seemed more elevated in supernatants of PKs and HKs co-cultured with IL-2-activated $\mathrm{T}$ lymphocytes than in IL-2-activated T lymphocytes alone. These data, however, were not shown as normalization of IFN- $\gamma$ concentrations with respect to lymphocyte numbers was not possible adequately because of the prolonged periods of co-cultures. In addition, IL-4, IL-10 and SCD40L were detected in supernatants of IL-2-activated $\mathrm{T}$ lymphocytes only, and were not affected by PKs or HKs (data not shown).

\section{PKs have an Altered Production of IL-1s and IL-1Ra Modulated by IL-2-Activated T Lymphocytes}

Since the 1990s, the exact expression pattern by PKs of major inflammatory mediators like the IL-1 members remains a controversial issue. ${ }^{32-37}$ Interestingly, IL- $1 \alpha$, IL- $1 \beta$ and IL-1Ra produced by HKs and PKs were differentially regulated with respect to the above proinflammatory cytokines. IL- $1 \alpha$
Table 2 Production of cytokines and chemokines by normal human $\mathrm{T}$ lymphocytes

\begin{tabular}{lcc}
\hline Cytokines/chemokines & T lymphocytes alone & T lymphocytes+IL-2 \\
\hline TNF- $\alpha$ & $6.7 \pm 3.6$ & $44.4 \pm 14.3^{\mathrm{a}}$ \\
IFN- $\gamma$ & $\mathrm{ND}$ & $82.0 \pm 36.5^{\mathrm{b}}$ \\
IL-6 & $1.3 \pm 1.3$ & $53.8 \pm 35.5$ \\
GM-CSF & $27.9 \pm 9.3$ & $109.9 \pm 60.4$ \\
IL-15 & $\mathrm{ND}$ & $\mathrm{ND}$ \\
IL-17 & $\mathrm{ND}$ & $\mathrm{ND}$ \\
SIL-2R $\alpha$ & $18.6 \pm 5.1$ & $71.2 \pm 19.4^{\mathrm{c}}$ \\
IL-1 $\alpha$ & $\mathrm{ND}$ & $\mathrm{ND}$ \\
IL-1 $\beta$ & $\mathrm{ND}$ & $\mathrm{ND}$ \\
IL-1Ra & $\mathrm{ND}$ & $\mathrm{ND}$ \\
IL-1Ra/IL-1 & - & - \\
IL-8 & $175.1 \pm 48.5$ & $750.3 \pm 378.1$ \\
MCP-1 & $806 \pm 237$ & $1375 \pm 563$ \\
IP-10 & $2.7 \pm 1.7$ & $397 \pm 125^{\mathrm{d}}$ \\
Fractalkine & $\mathrm{ND}$ & $\mathrm{ND}$ \\
& &
\end{tabular}

ND, non-detectable.

Normal human T lymphocytes $\left(2 \times 10^{6} / \mathrm{ml}\right)$ were cultured in DMEM/F $12+5 \%$ FetalClone II to evaluate the accumulation of cytokines/chemokines in supernatants after 13 days. The analytes TNF- $\alpha$, IFN- $\gamma$, IP-10, IL-6, MCP-1, IL- $1 \beta$, GM-CSF, IL-15, sIL-2R $\alpha$ and fractalkine were evaluated by using the Luminex XMAP technology, and IL-1 $\alpha$, IL-1Ra and IL- 8 were measured by using EIA kits. In the ratio IL-1Ra/LL-1, IL-1 represents the sum of IL- $1 \alpha+\mathrm{IL}-1 \beta$.

${ }^{*}$ Results are expressed as means \pm s.e.m. in $\mathrm{pg} / \mathrm{ml}$ per million of healthy T lymphocytes $(n=8)$.

Statistical analysis (two-tailed $t$-test, alone $v s+\mathrm{IL}-2$ ).

${ }^{\mathrm{a}} P=0.0210$.

${ }^{\mathrm{b}} P=0.0390$.

${ }^{\mathrm{c}} P=0.0189$.

$\mathrm{d}_{P=0.0192}$.

and IL-1Ra measured in the supernatants of PKs were reduced comparatively to $\mathrm{HKs}(\mathrm{PK} / \mathrm{HK}=0.5$ and 0.2 , respectively), while IL- $1 \beta$ was increased by a factor of 7.7. As a consequence, the ratio of IL-1Ra/IL-1s (PKs $v s$ HKs) that reflects the anti-inflammatory potential of IL-1Ra was reduced (Table 1). The IL-1 response of keratinocytes to the presence of $\mathrm{T}$ lymphocytes was also different from that for the above cytokines. T lymphocytes without IL-2 were unable to influence IL- $1 \alpha$, IL- $1 \beta$ and IL-1Ra produced by HKs and PKs, as well as the ratio IL-1Ra/IL-1s (Figures 3a, c and $4 \mathrm{a}, \mathrm{c})$. The most surprising effects were obtained with IL-2-activated T lymphocytes, the sole condition that was able to modulate HK and PK production of IL-1s. Thus, HK and PK production of IL- $1 \alpha$ was upregulated in the presence of IL-2-activated T lymphocytes by a factor of 1.7 and 6.8 , respectively. IL-1 $\beta$ and IL-1Ra production by HKs remained unchanged by the presence of IL-2-activated T lymphocytes (Figures $3 \mathrm{~b}$ and $4 \mathrm{~b}$ ). PK production of IL- $1 \beta$ in the presence of IL-2-activated T lymphocytes was not 
a
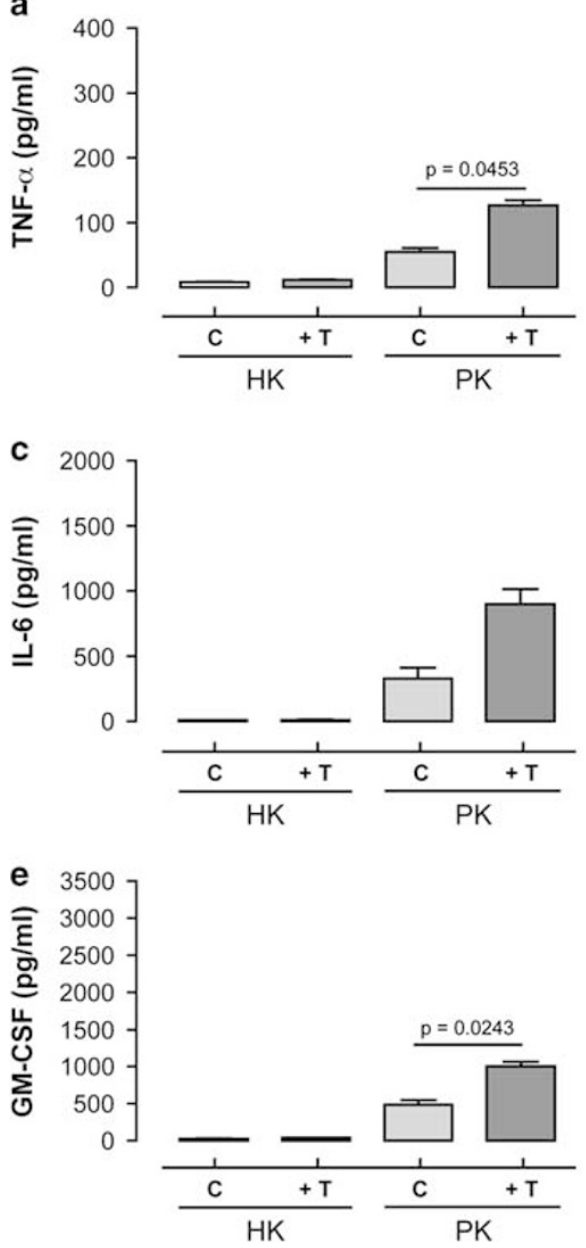
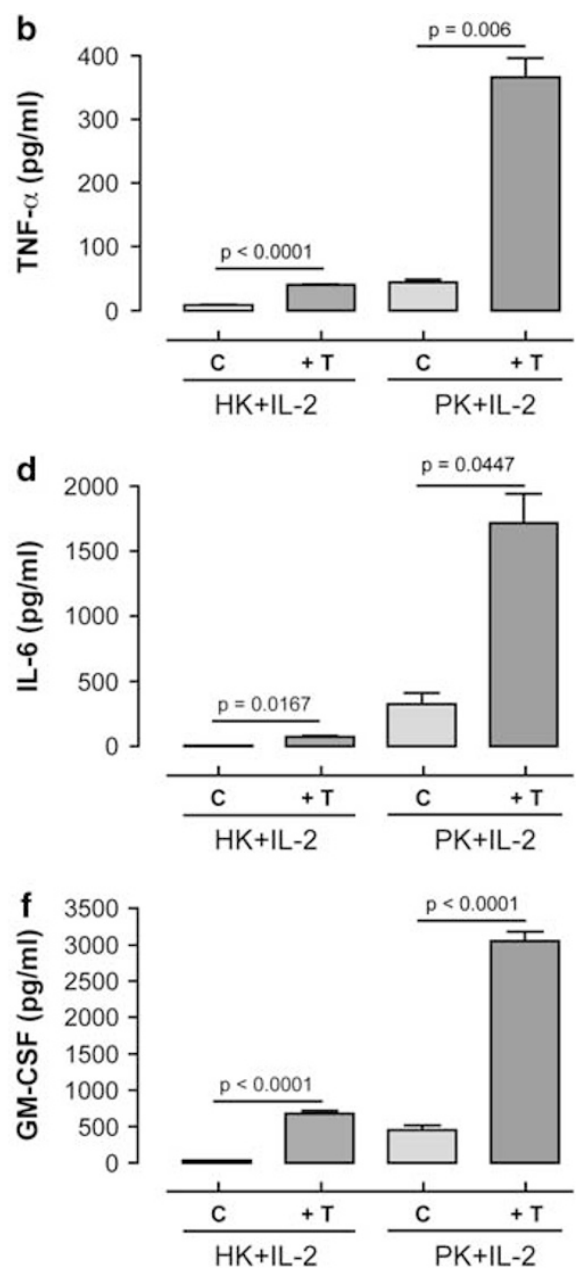

Figure 2 Tumor necrosis factor (TNF)- $\alpha$, interleukin (IL)-6 and granulocyte-macrophage colony-stimulating factor (GM-CSF) production by keratinocytes. Healthy (HKs) or psoriatic (PKs) keratinocytes $\left(1.3 \times 10^{4}\right.$ cells per $\left.\mathrm{cm}^{2}\right)$ were seeded with $(+\mathrm{T})$ or without $(\mathrm{C})$ normal human $\mathrm{T}$ lymphocytes $\left(2 \times 10^{6}\right)$ in the presence of vehicle $(\mathbf{a}, \mathbf{c}, \mathbf{e})$ or recombinant human $(\mathbf{r h}) \mathrm{IL}-2(\mathbf{b}, \mathbf{d}, \mathbf{f})$ for 13 days at $37^{\circ} \mathrm{C}$. Supernatants were collected at day 13 and frozen until assayed for TNF- $\alpha(\mathbf{a}, \mathbf{b})$, IL-6 (c, d) and GM-CSF (e, f) by multiplex assay (TNF- $\alpha$, GM-CSF) and enzyme-linked immunosorbent assay (ELISA) (IL-6). Results are expressed as mean \pm s.e.m. per $10^{6}$ keratinocytes. Statistics: unpaired $t$-test (lymphocytes: $n=9$; PKs: $n=3$; HKs: $n=2$ ).

modified, while that of IL-1Ra was increased by a factor of 2.5 (Figures $3 \mathrm{~d}$ and $4 \mathrm{~b}$ ). However, the PK IL-1Ra/IL-1 ratio was not changed by the presence of IL-2-activated T lymphocytes (Figure 4d).

\section{IL-2-Activated T Lymphocytes Drastically Increased the Production of Chemokines by PKs}

In parallel to cytokines that allow intercellular communications, multiple chemokines that regulate cell movements are essential components of the pathogenesis of psoriasis plaques. $^{23,24}$ PKs produced IL-8 (CXCL8), MCP-1 (CCL2) and IP-10 (CXCL10) to an extent greater than did HKs by a factor of 3.9, 2.6 and 10.1, respectively. On the other hand, fractalkine (CX3CL1) was similarly produced by both types of keratinocytes (Table 1). Eotaxin (CCL11) was under the detection limit in all the conditions studied (data not shown). Interestingly, the presence of $\mathrm{T}$ lymphocytes in cul- tures of PKs was associated with an increase of IL-8, MCP-1 and IP-10 by a factor of $1.9,19$ and 4.1, respectively (Table 3 ). In contrast, $\mathrm{HK}$ co-incubated with $\mathrm{T}$ lymphocytes had no increase of IL-8, IP-10 and fractalkine (Figures 5a and 6a, c). The presence of $\mathrm{T}$ lymphocytes tended to increase the production of MCP-1 by HKs (Figure 5c).

Once again, the most striking effects were recorded with IL-2-activated $\mathrm{T}$ lymphocytes (Figures $5 \mathrm{~b}, \mathrm{~d}$ and $6 \mathrm{~b}, \mathrm{~d}$ ). In these conditions ( $v s$ PKs alone), PKs increased their production of IL-8, MCP-1 and IP-10 by a factor of 2.9, 52 and 36.2, respectively. Similarly, HKs, which had a basal output of these chemokines lower than that of PKs, also augmented their production of IL-8, MCP-1 and IP-10 $(\times 3.1, \times 138$ and $\times 64.6$, respectively). The most intriguing result was obtained with fractalkine, which was greatly overproduced $(\times 32.5)$ by PKs with IL-2-activated T lymphocytes only (Figure 6d). 
Table 3 Production of cytokines and chemokines by HKs and PKs in the presence of normal $\mathrm{T}$ cells

\begin{tabular}{lcccc}
\hline $\begin{array}{l}\text { Cytokines/ } \\
\text { chemokines }\end{array}$ & HK+T cells & PK+T cells & PK+T/HK+T & PK+T/PK \\
\hline TNF- $\alpha$ & $11.7 \pm 2.8$ & $127 \pm 25^{\mathrm{a}}$ & 10.9 & 2.3 \\
IFN- $\gamma$ & $\mathrm{ND}$ & $\mathrm{ND}$ & - & - \\
IL-6 & $10.6 \pm 4.0$ & $99.8 \pm 25.4^{\mathrm{b}}$ & 9.4 & 2 \\
GM-CSF & $44.0 \pm 5.7$ & $1006 \pm 166^{\mathrm{c}}$ & 22.9 & 3.4 \\
IL-15 & $7.2 \pm 4.6$ & $16.0 \pm 12.6$ & $\mathrm{NC}$ & $\mathrm{NC}$ \\
IL-17 & $\mathrm{ND}$ & $\mathrm{ND}$ & - & - \\
SIL-2R $\alpha$ & $5.8 \pm 8.2$ & $7.0 \pm 10.8$ & $\mathrm{NC}$ & - \\
IL-1 $\alpha$ & $312 \pm 43$ & $267 \pm 50$ & $\mathrm{NC}$ & 1.8 \\
IL-1 $\beta$ & $18.3 \pm 1.8$ & $300 \pm 83^{\mathrm{d}}$ & 16.4 & 2.1 \\
IL-1Ra & $149674 \pm 12733$ & $17910 \pm 8250^{\mathrm{e}}$ & 0.1 & 0.6 \\
IL-1Ra/IL-1 & 454 & 32 & - & - \\
IL-8 & $1301 \pm 253$ & $7197 \pm 1696^{\mathrm{f}}$ & 5.5 & 1.9 \\
MCP-1 & $2423 \pm 1187$ & $5410 \pm 1219^{\mathrm{g}}$ & 2.2 & 19 \\
IP-10 & $390 \pm 98$ & $7731 \pm 1904^{\mathrm{h}}$ & 19.8 & 4.1 \\
Fractalkine & $27.4 \pm 12.6$ & $181 \pm 43^{\mathrm{i}}$ & 6.6 & 1.9 \\
\hline & & & & \\
\hline
\end{tabular}

ND, non-detectable; NC, no change.

Keratinocytes (K) were cultured in DMEM/F12+5\% FetalClone II to evaluate the accumulation of cytokines/chemokines in supernatants after 13 days. The analytes TNF- $\alpha$, IFN- $\gamma$, IP-10, IL-6, MCP-1, IL-1 $\beta$, GM-CSF, IL-15, sIL-2R $\alpha$ and fractalkine were evaluated by using the Luminex XMAP technology, and IL-1 $\alpha$ IL-1Ra and IL-8 were measured by using EIA kits. In the ratio IL-1Ra/IL-1, IL-1 represents the sum of IL- $1 \alpha+\mathrm{IL}-1 \beta$.

Results are expressed as means \pm s.e.m. in $\mathrm{pg} / \mathrm{ml}$ per million of healthy (HKs, $n=8$ ) and psoriatic keratinocytes (PKs, $n=9$ ) co-cultured with T cells in the absence of IL-2.

Statistical analysis (two-tailed $t$-test, $\mathrm{HK}+\mathrm{T}$ cells vs $\mathrm{PK}+\mathrm{T}$ cells).

$a_{\star P}=0.006$.

$\mathrm{b}_{P}=0.0121$.

${ }^{c} P=0.0008$

$\mathrm{d}_{P=0.0351}$.

$\mathrm{e}_{P}<0.0001$.

$\mathrm{f}_{P}=0.0313$.

$\mathrm{g}_{P}=0.0077$.

$\mathrm{h}_{P}=0.0180$.

${ }^{\mathrm{i}} P=0.0271$.

\section{VEGF Is Produced by Keratinocytes Independently} of IL-2-Activated T Lymphocytes

Increased expression of VEGF in lesional psoriatic skin, its overexpression by PKs and its link with disease severity have been documented. ${ }^{38-40}$ In the present experimental conditions, both keratinocyte types showed a high basal output of VEGF. Although PKs seemed to generate VEGF to an extent greater than that of HKs $(12750 \pm 2362$ and $9756 \pm 1110 \mathrm{pg} / \mathrm{ml}$ per $10^{6}$ cells, respectively), the difference was not however significant (Figure 7a). Surprisingly, T lymphocytes with or without IL-2 activation did not affect VEGF produced by PKs and HKs (Figures $7 \mathrm{a}$ and $\mathrm{b}$ ).

\section{The Crosstalk Between Keratinocytes and T Cells Requires Cell-to-Cell Interactions}

Cytokines and chemokines from lymphocytes have the capacity of stimulating keratinocytes. ${ }^{41,42}$ In addition, activation of keratinocytes like that of PKs promotes the adherence of allogenic and autologous $\mathrm{T}$ lymphocytes to these keratinocytes. ${ }^{31,43,44}$ However, the possible functional role of direct contact between keratinocytes and lymphocytes has never been addressed. Coculture of keratinocytes with $\mathrm{T}$ lymphocytes was designed to avoid cell-to-cell contact by placing lymphocytes on top of porous membranes. Interestingly, the absence of direct cellular contact was associated with a significant reduction of cytokine and chemokine production. By avoiding direct cellular contact, PK production of cytokines and chemokines in the presence of IL-2activated $\mathrm{T}$ lymphocytes was decreased (Figure 8). The most striking reduction of production in the absence of cell contact was obtained for TNF- $\alpha$, IL-6, GM-CSF, IL- $1 \alpha$, MCP-1, IP-10 and fractalkine. These results indicate that, to be optimally functional, interactions between PKs and T lymphocytes absolutely require a direct cell contact.

\section{DISCUSSION}

The abnormalities leading to psoriasis development remains controversial; however, the crosstalk between cells of the epidermis, the keratinocytes, and $\mathrm{T}$ lymphocytes represents a necessary step during the course of the disease, ${ }^{45}$ and consequently a potential therapeutic target that has been confirmed by the efficacy of various biologics. ${ }^{46}$ As allogenic $\mathrm{T}$ lymphocytes can bind to keratinocytes, ${ }^{44}$ we addressed the possible reciprocal crosstalk of PKs with normal allogenic T lymphocytes by using a model of psoriatic skin we recently set up and that allowed to show that PKs, more than HKs, increased the survival of normal $\mathrm{T}$ lymphocytes. ${ }^{26,29}$ Moreover, experiments with normal $\mathrm{T}$ lymphocytes has the advantage of simplifying the interpretation about the role of PKs. Our findings support the hypothesis that our model has the capacity of showing alterations of the intercellular communications between keratinocytes and normal allogenic T lymphocytes. Thus, PKs more than HKs were functionally affected by $\mathrm{T}$ lymphocytes, mainly in the presence of IL-2activated lymphocytes. To obtain optimal functions during cell crosstalk, a direct cell contact between both cell types was a prerequisite condition.

A major issue in setting up a new in vitro model for pharmacology studies is to validate this model compared to the in vivo situation and previous experimental results published. As a first result from the present report, the culture conditions of keratinocytes have allowed to show significant differences of cytokine and chemokine expression between PKs and HKs, PKs being more productive than HKs for TNF- $\alpha$, IL-6, GM-CSF, IL- $1 \beta$, IL-8, MCP-1 and IP-10. These results are in agreement with different reports in the literature. $^{1,24,30}$ Concerning fractalkine and VEGF that were also found elevated in PKs, the nonsignificant difference with 

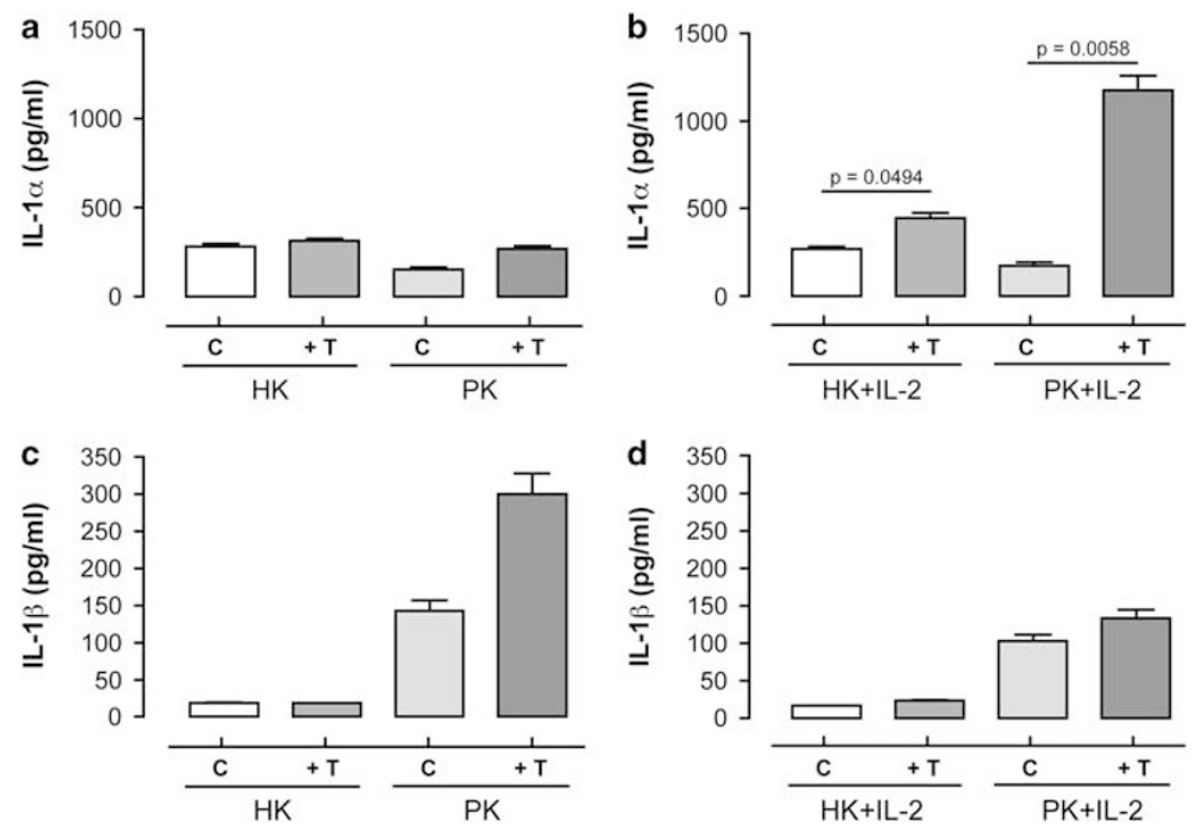

Figure 3 Extracellular interleukin (IL)- $1 \alpha$ and IL-1 $\beta$ production by keratinocytes. Healthy (HKs) or psoriatic (PKs) keratinocytes $\left(1.3 \times 10^{4}\right.$ cells per $\mathrm{cm}^{2}$ ) were seeded with $(+\mathrm{T})$ or without $(\mathrm{C})$ normal human T lymphocytes $\left(2 \times 10^{6}\right)$ in the presence of vehicle $(\mathbf{a}, \mathbf{c})$ or recombinant human $(\mathrm{rh}) \mathrm{IL}-2(\mathbf{b}$, d) for 13 days at $37^{\circ} \mathrm{C}$. Supernatants were collected at day 13 and frozen until assayed for IL- $1 \alpha(\mathbf{a}, \mathbf{b})$ and IL-1 $\beta$ (c, d) by multiplex assay and enzyme-linked immunosorbent assay (ELISA), respectively. Results are expressed as mean \pm s.e.m. per $10^{6}$ keratinocytes. Statistics: unpaired $t$-test (lymphocytes: $n=9$; PKs: $n=3$; HKs: $n=2$ ).
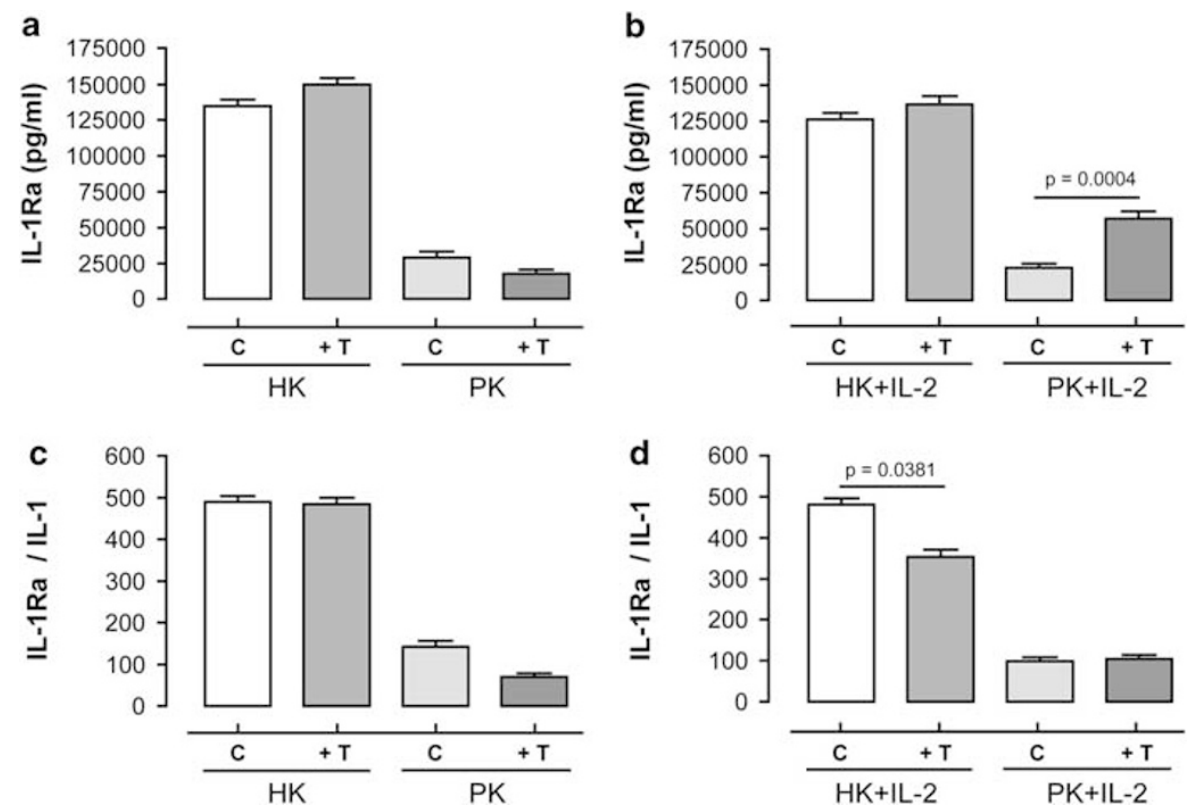

Figure 4 Extracellular interleukin (IL)-1Ra production by keratinocytes. Experimental conditions were similar to those above. Healthy (HKs) or psoriatic (PKs) keratinocytes were seeded with $(+\mathrm{T})$ or without $(C)$ normal human T lymphocytes in the presence of vehicle $(\mathbf{a}, \mathbf{c})$ or recombinant human (rh) IL-2 (b, d) for 13 days at $37^{\circ} \mathrm{C}$. IL-1 Ra was evaluated by enzyme-linked immunosorbent assay (ELISA). IL-1Ra/IL-1 corresponds to the ratio of IL-1Ra/IL-1 $\alpha+$ IL-1 $\beta$ in similar experiments. Results are expressed as mean \pm s.e.m. per $10^{6}$ keratinocytes. Statistics: unpaired $t$-test (lymphocytes: $n=9$; psoriatic keratinocytes (PKs): $n=3$; healthy keratinocytes (HKs): $n=2$ ).

HKs could be related to the low number of PKs studied. Interestingly, we also showed that PKs produced less IL- $1 \alpha$ and more IL-1 $\beta$ than HKs, as reported previously. ${ }^{33,47}$ IL1-Ra produced by PKs was decreased compared with HKs, a result that is different from previous reports. ${ }^{48,49}$ However, we evaluated the extracellular production of IL-1Ra only 

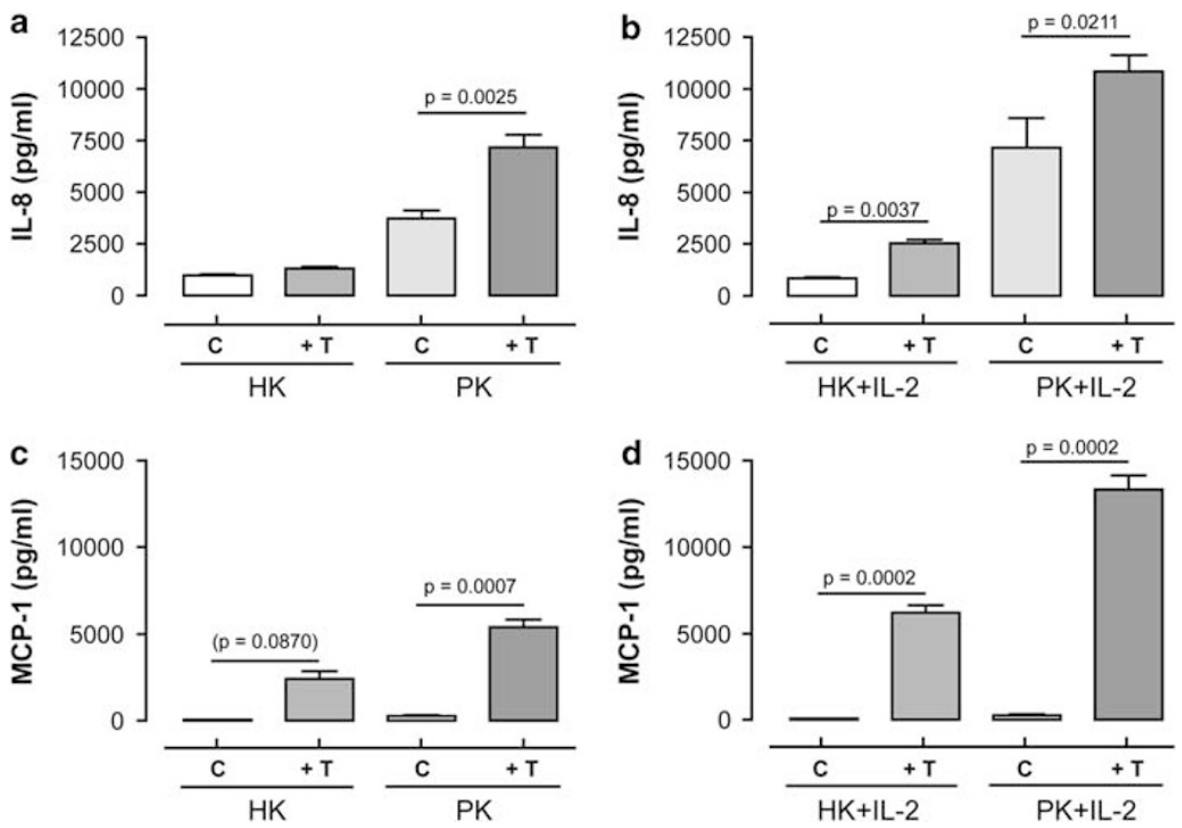

Figure 5 Interleukin (IL)-8 and monocyte chemotactic protein-1 (MCP-1) production by keratinocytes. Experimental conditions were similar to those above. Healthy (HKs) or psoriatic (PKs) keratinocytes were seeded with $(+\mathrm{T})$ or without $(\mathrm{C})$ normal human T lymphocytes in the presence of vehicle $(\mathbf{a}$, $\mathbf{c})$ or recombinant human (rh) IL-2 (b, d) for 13 days at $37^{\circ} \mathrm{C}$. IL-8 and MCP-1 were measured by enzyme-linked immunosorbent assay (ELISA). Results are expressed as mean \pm s.e.m. per $10^{6}$ keratinocytes. Statistics: unpaired $t$-test (lymphocytes: $n=9$; psoriatic keratinocytes (PKs): $n=3$; human keratinocytes (HKs: $n=2)$.
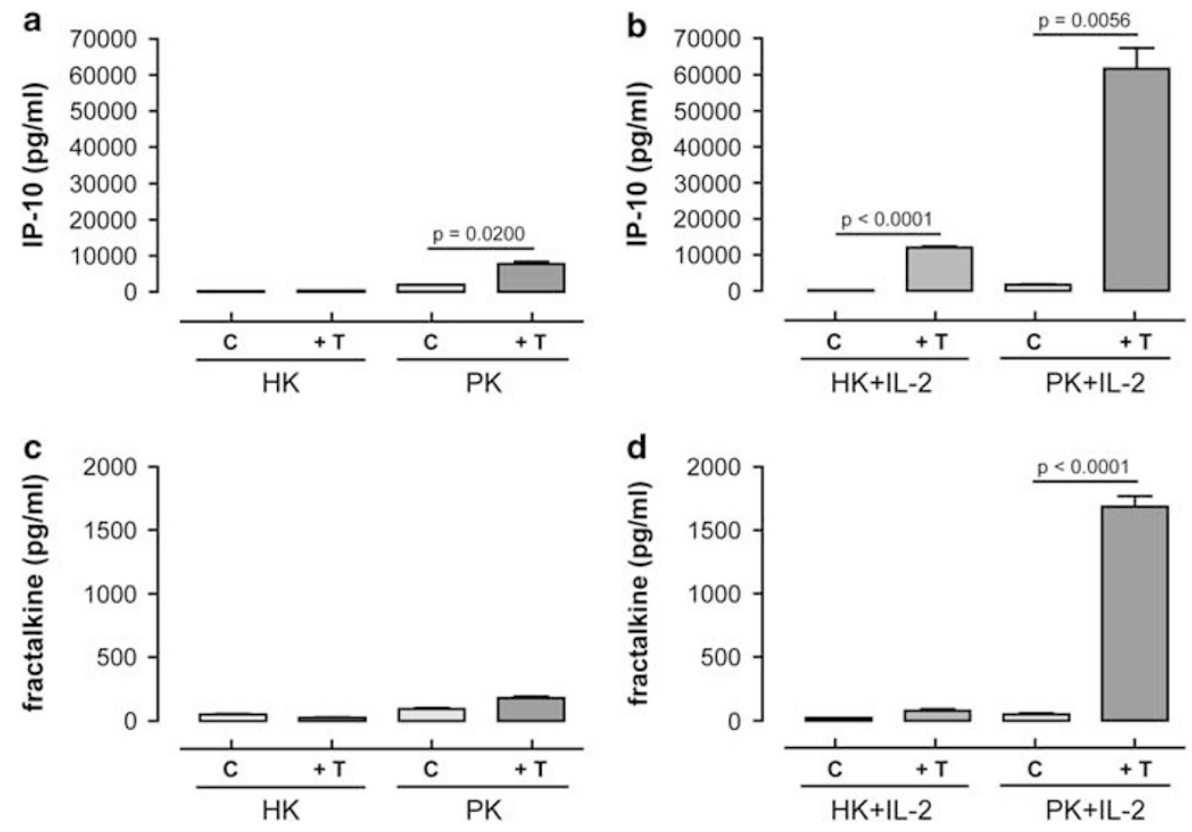

Figure 6 Interferon- $\gamma$-induced protein $10 \mathrm{kDa}$ (IP-10) and fractalkine production by keratinocytes. Experimental conditions were similar to those above. Healthy (HKs) or psoriatic (PKs) keratinocytes were seeded with $(+\mathrm{T})$ or without $(C)$ normal human $\mathrm{T}$ lymphocytes in the presence of vehicle $(\mathbf{a}$, $\mathbf{c})$ or recombinant human (rh) IL-2 (b, d) for 13 days at $37^{\circ} \mathrm{C}$. IP-10 and fractalkine were measured by enzyme-linked immunosorbent assay (ELISA). Results are expressed as mean \pm s.e.m. per $10^{6}$ keratinocytes. Statistics: unpaired $t$-test (lymphocytes: $n=9$; psoriatic keratinocytes (PKs): $n=3$; human keratinocytes (HKs): $n=2$ ).

that was not necessarily representative of this cytokine mainly stocked inside the cell. ${ }^{50}$ A second more important result was the reciprocal impact of keratinocytes and $\mathrm{T}$ lymphocytes on cytokines and chemokines. The confocal visualization of concentrated dye located in the section of lymphocyte membrane directly adherent to PKs allowed to consider functional cell interactions. In fact, independent of the major impact of IL-2-activated T lymphocytes on 

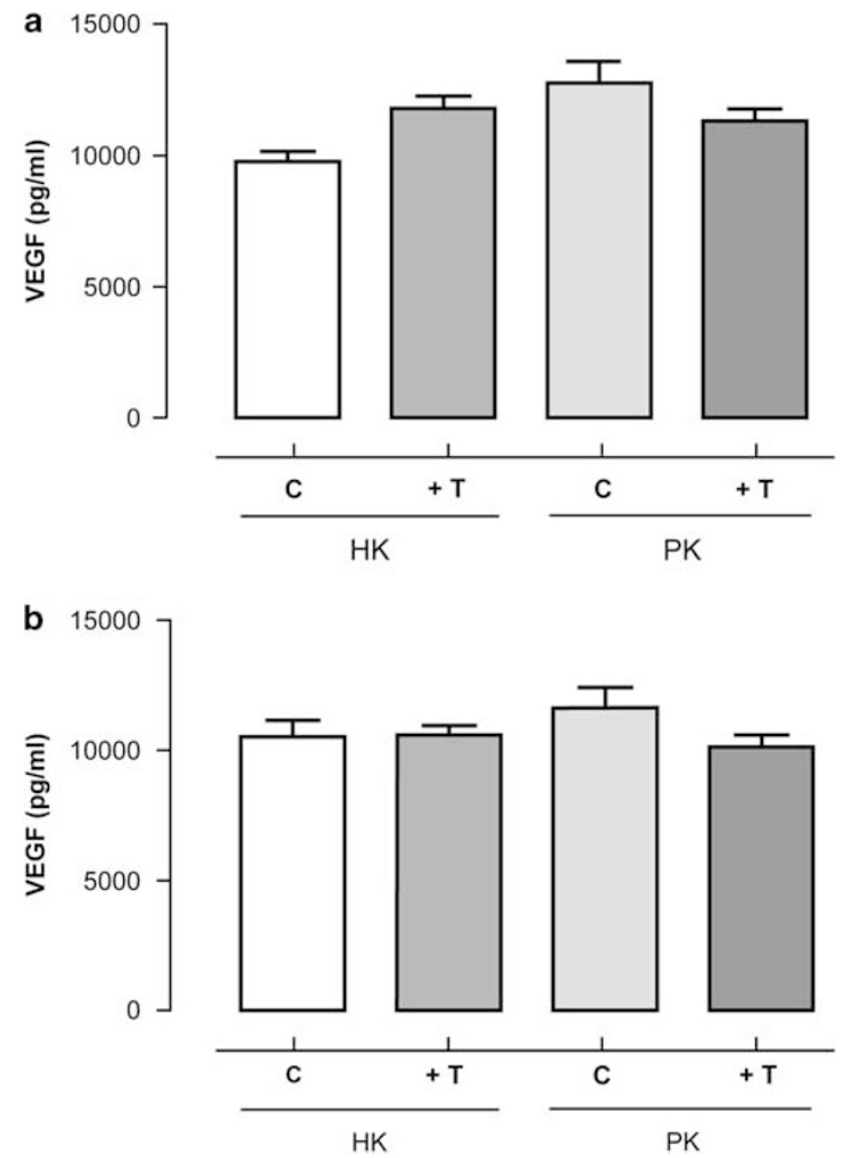

Figure 7 Vascular endothelial growth factor (VEGF) production by keratinocytes. Experimental conditions were similar to those above. VEGF was measured by enzyme-linked immunosorbent assay (ELISA). Healthy (HKs) or psoriatic (PKs) keratinocytes were seeded with $(+\mathrm{T})$ or without $(\mathrm{C})$ normal human $T$ lymphocytes in the presence of vehicle (a) or recombinant human (rh) IL-2 (b) for 13 days at $37^{\circ} \mathrm{C}$. Results are expressed as mean \pm s.e.m. per $10^{6}$ keratinocytes. Statistics: unpaired $t$-test (lymphocytes: $n=9$; psoriatic keratinocytes (PKs): $n=3$; human keratinocytes (HKs): $n=2$ ).

PKs, as reported previously, ${ }^{6,25}$ the present model showed that non-activated $\mathrm{T}$ lymphocytes had the capacity to affect PKs as well as HKs depending on the cytokines or chemokines studied. Finally, the necessity of a direct contact between PKs and T lymphocytes to obtain an optimal profile of cytokine and chemokine production was demonstrated for the first time that confirms the usefulness of our experimental model.

Interestingly, the prerequisite condition of a direct cell contact to obtain functional interactions between keratinocytes and IL-2-activated T lymphocytes raises the importance of $\mathrm{T}$ lymphocyte penetration across the keratinocyte layers that lead to psoriasis skin lesions. Migration of lymphocytes through tightly connected keratinocytes is associated with disruption of desmosomes, ${ }^{51}$ which is an early event in psoriasis, ${ }^{52}$ and which implies direct contact between migrating lymphocytes and keratinocytes. In addition, T lymphocyte migration into the psoriatic epidermis implicates adhesion molecules like LFA-1 and ICAM-1, respectively, expressed by these two cell types. ${ }^{43,53}$ Thus, our results of direct cell contact requirement for a functional cell crosstalk is in agreement with the histopathology of psoriasis. It is also useful to point out that our results also indicate the capacity and the importance of PKs to activate normal T lymphocytes.

Fractalkine has been reported to be greatly found in psoriasis lesions and overproduced by antigen-presenting cells as well as keratinocytes. ${ }^{54-56}$ However, no indication was available on the role of lymphocytes, which do not produce this chemokine, in driving keratinocytes to generate fractalkine. The basal output of fractalkine produced by PKs, although more elevated than that produced by HKs, remained very low even in the presence of $\mathrm{T}$ lymphocytes. However, the production of fractalkine by $\mathrm{PKs}$ in the presence of IL-2-activated T lymphocytes was drastically increased (by a factor of 32), a condition that required absolutely a direct contact between both cell types. Considering the pathophysiology of psoriasis, this result highlights the role of lesional PKs, but mainly that of activated lymphocytes.

The dermis of psoriasis skin lesions was shown to be the major source of Th17 cells, as well as of myeloid dermal dendritic cells that drive lymphocytes to Th1/Th17 cells, an effect that was not found with normal dermal dendritic cells. ${ }^{15,16}$ These published results could be essential in relation to our present findings of the absence of detectable IL-17 in IL-2-activated T lymphocytes, even in the presence of PKs (Tables 2 and 3), that indicate a major pathogenic role of Th1/ Th17 lymphocytes from the dermis of psoriasis skin lesions. Interestingly, psoriatic dermal dendritic cells have also been shown to be the main source of IL-23, which is responsible for the expansion of Th17 cells. ${ }^{57,58}$ Recently, another T-cell subset independent of Th1, Th2 and Th17 cells, the Th22 lymphocytes, have been found in the epidermis of psoriasis skin lesions, and were shown to induce a specific activation of keratinocytes. ${ }^{59}$ It is also worth noting that Th1, Th17 and Th22 lymphocytes were found elevated in the blood of patients with psoriasis, and that mast cells and neutrophils of psoriasis skin lesions were reported as providers of IL-17..$^{60,61}$ Taken together, these results open interesting experimental avenues for further functional studies using our model of keratinocyte interactions with the different subsets of $\mathrm{T}$ cells, mast cells and neutrophils from patients with psoriasis.

Keratinocytes can produce angiogenic factors, notably VEGF that affects greatly the endothelium; ${ }^{62}$ however, keratinocytes in the presence of various cytokines did not increase their production of VEGF. Interestingly, we found that PKs and HKs both produced large amounts of VEGF, but did not respond to the presence of $\mathrm{T}$ lymphocytes with or without IL-2 activation. Before extrapolating these results to the absence of a relation between lymphocyte and VEGF production by keratinocytes, it remains necessary to test the effects of psoriatic lymphocytes in the same experimental conditions. However, considering our present overall results on the selective involvement of $\mathrm{T}$ lymphocytes in responding to and 

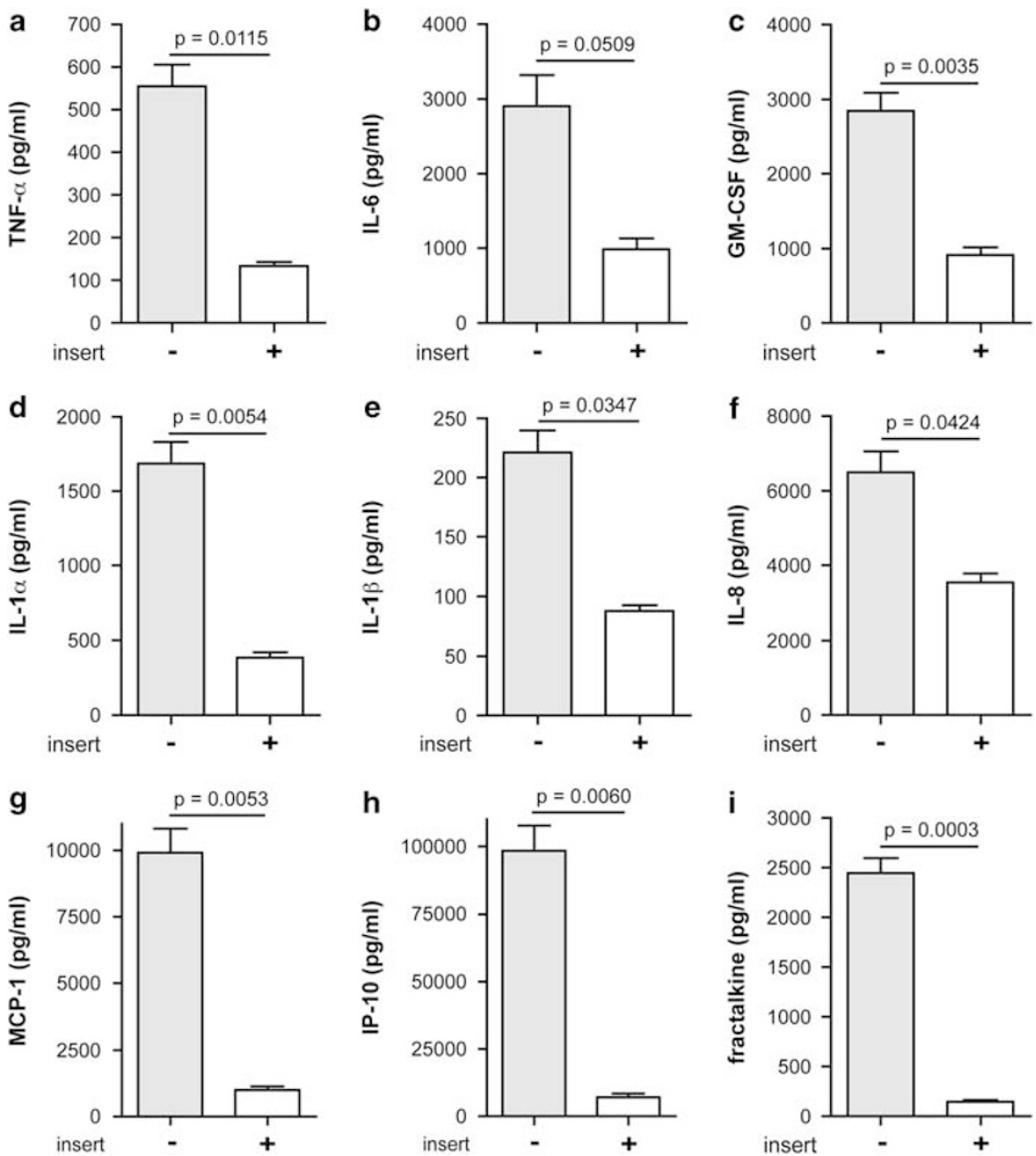

Figure 8 Influence of cell-to-cell interaction in the production of cytokines and chemokines by psoriatic keratinocytes. Psoriatic keratinocytes + interleukin-2activated T lymphocytes were cultured as above, with or without a cell culture insert to avoid direct cellular contact. Tumor necrosis factor (TNF)- $\alpha$ (a), IL-6 (b), granulocyte-macrophage colony-stimulating factor (GM-CSF) (c), IL-1 $\alpha$ (d), IL-1 $\beta$ (e), IL-8 (f), monocyte chemotactic protein-1 (MCP-1) (g), interferon- $\gamma$ induced protein $10 \mathrm{kDa}(\mathrm{IP}-10)(\mathbf{h})$ and fractalkine (i) were evaluated by multiplex assay. Results are expressed as mean \pm s.e.m. per $10^{6}$ keratinocytes.

Statistics: paired $t$-test (lymphocytes: $n=3$; psoriatic keratinocytes (PKs): $n=3$ ).

in stimulating the keratinocytes to produce certain factors, it will be greatly possible that VEGF from keratinocytes escapes regulation by lymphocytes.

In conclusion, by using the present in vitro model, the addition of different cell types that constitute the in vivo conditions allows to validate the respective role of keratinocytes and T lymphocytes. It will also permit to decipher the mechanisms of cell interactions and future studies of their modulation by drugs.

\section{ACKNOWLEDGEMENTS}

$\mathrm{R}$ Pouliot was recipient of a research fellowship from the 'Fonds de la Recherche en Santé du Québec' (QC, Canada). S Guérard acknowledges the 'Fonds de recherche en santé du Québec' and the 'Fonds d'enseignement et de recherche' of the Faculté de Pharmacie of Université Laval (QC, Canada) for his graduate scholarships. M-M Rosa Fortin was recipient of a scholarship from the 'Fonds d'enseignement et de recherche' of the Faculty of Pharmacy (Université Laval, Québec, QC), and of a graduate scholarship from the CIHR. This work was supported by a grant from the Canadian Institutes of Health Research (CIHR) to Drs R Pouliot and PE Poubelle.

\section{DISCLOSURE/CONFLICT OF INTEREST}

The authors declare no conflict of interest.

1. Nestle FO, Kaplan DH, Barker J. Psoriasis. N Engl J Med 2009;361: 496-509.

2. Griffiths CE, Barker JN. Pathogenesis and clinical features of psoriasis. Lancet 2007;370:263-271.

3. Shuster S. Research into psoriasis-the last decade. BMJ 1971;3: 236-239.

4. Weinstein GD, Frost P. Abnormal cell proliferation in psoriasis. J Invest Dermatol 1968;50:254-259.

5. Powles AV, Baker BS, Valdimarsson $\mathrm{H}$, et al. Four years of experience with cyclosporin A for psoriasis. Br J Dermatol 1990;122(Suppl 36):13-19.

6. Wrone-Smith T, Nickoloff BJ. Dermal injection of immunocytes induces psoriasis. J Clin Invest 1996;98:1878-1887.

7. Sabat R, Philipp S, Hoflich $C$, et al. Immunopathogenesis of psoriasis. Exp Dermatol 2007;16:779-798. 
8. Nickoloff BJ, Nestle FO, Zheng XG, et al. T lymphocytes in skin lesions of psoriasis and mycosis fungoides express B7-1: a ligand for CD28. Blood 1994;83:2580-2586.

9. Nikaein A, Phillips C, Gilbert SC, et al. Characterization of skininfiltrating lymphocytes in patients with psoriasis. J Invest Dermatol 1991;96:3-9.

10. Menssen A, Trommler $\mathrm{P}$, Vollmer $\mathrm{S}$, et al. Evidence for an antigenspecific cellular immune response in skin lesions of patients with psoriasis vulgaris. J Immunol 1995;155:4078-4083.

11. Abrams JR, Lebwohl MG, Guzzo CA, et al. CTLA4lg-mediated blockade of T-cell costimulation in patients with psoriasis vulgaris. J Clin Invest 1999;103:1243-1252.

12. Gottlieb SL, Gilleaudeau $P$, Johnson $R$, et al. Response of psoriasis to a lymphocyte-selective toxin (DAB389IL-2) suggests a primary immune, but not keratinocyte, pathogenic basis. Nat Med 1995;1: 442-447.

13. Prinz J, Braun-Falco O, Meurer $M$, et al. Chimaeric CD4 monoclonal antibody in treatment of generalised pustular psoriasis. Lancet 1991; 338:320-321.

14. Nestle FO, Turka LA, Nickoloff BJ. Characterization of dermal dendritic cells in psoriasis. Autostimulation of $T$ lymphocytes and induction of Th1 type cytokines. J Clin Invest 1994;94:202-209.

15. Zaba LC, Fuentes-Duculan J, Eungdamrong NJ, et al. Psoriasis is characterized by accumulation of immunostimulatory and Th1/Th17 cell-polarizing myeloid dendritic cells. J Invest Dermatol 2009;129: 79-88.

16. Lowes MA, Kikuchi T, Fuentes-Duculan J, et al. Psoriasis vulgaris lesions contain discrete populations of Th1 and Th17 T cells. J Invest Dermato 2008;128:1207-1211.

17. Austin LM, Ozawa M, Kikuchi $\mathrm{T}$, et al. The majority of epidermal T cells in Psoriasis vulgaris lesions can produce type 1 cytokines, interferon-gamma, interleukin-2, and tumor necrosis factor-alpha, defining TC1 (cytotoxic T lymphocyte) and TH1 effector populations: a type 1 differentiation bias is also measured in circulating blood $T$ cells in psoriatic patients. J Invest Dermatol 1999;113:752-759.

18. Boyman O, Hefti HP, Conrad C, et al. Spontaneous development of psoriasis in a new animal model shows an essential role for resident T cells and tumor necrosis factor-alpha. J Exp Med 2004;199: 731-736.

19. Bata-Csorgo Z, Hammerberg C, Voorhees JJ, et al. Intralesional T-lymphocyte activation as a mediator of psoriatic epidermal hyperplasia. J Invest Dermatol 1995;105:89S-94S

20. Bata-Csorgo Z, Hammerberg C, Voorhees JJ, et al. Kinetics and regulation of human keratinocyte stem cell growth in short-term primary ex vivo culture. Cooperative growth factors from psoriatic lesional $\mathrm{T}$ lymphocytes stimulate proliferation among psoriatic uninvolved, but not normal, stem keratinocytes. J Clin Invest 1995;95: 317-327.

21. Prinz JC, Gross B, Vollmer $S$, et al. $T$ cell clones from psoriasis skin lesions can promote keratinocyte proliferation in vitro via secreted products. Eur J Immunol 1994;24:593-598.

22. Sano S, Chan KS, Carbajal S, et al. Stat3 links activated keratinocytes and immunocytes required for development of psoriasis in a novel transgenic mouse model. Nat Med 2005;11:43-49.

23. Lowes MA, Bowcock AM, Krueger JG. Pathogenesis and therapy of psoriasis. Nature 2007;445:866-873.

24. Nickoloff BJ, Xin H, Nestle FO, et al. The cytokine and chemokine network in psoriasis. Clin Dermatol 2007;25:568-573.

25. Chang EY, Hammerberg C, Fisher G, et al. T-cell activation is potentiated by cytokines released by lesional psoriatic, but not normal, epidermis. Arch Dermatol 1992;128:1479-1485.

26. Jean J, Lapointe M, Soucy J, et al. Development of an in vitro psoriatic skin model by tissue engineering. J Dermatol Sci 2009;53:19-25.

27. Germain L, Rouabhia M, Guignard R, et al. Improvement of human keratinocyte isolation and culture using thermolysin. Burns 1993;19: 99-104.

28. Chakravarti A, Marceau AA, Flamand $L$, et al. Normal human primary CD4+ T lymphocytes synthesize and release functional osteoprotegerin in vitro. Lab Invest 2008;88:171-184.

29. Rosa Fortin MM, Poubelle PE, Soucy J, et al. Cellular interactions in vitro: psoriatic keratinocytes enhance $\mathrm{T}$ lymphocyte survival. Psoriasis Forum 2010;16:12-15.
30. Albanesi C, De Pita O, Girolomoni G. Resident skin cells in psoriasis: a special look at the pathogenetic functions of keratinocytes. Clin Dermatol 2007:25:581-588.

31. Nickoloff BJ, Griffiths CE. T lymphocytes and monocytes bind to keratinocytes in frozen sections of biopsy specimens of normal skin treated with gamma interferon. J Am Acad Dermatol 1989;20:736-743.

32. Bigler CF, Norris DA, Weston WL, et al. Interleukin-1 receptor antagonist production by human keratinocytes. J Invest Dermatol 1992;98:38-44.

33. Cooper KD, Hammerberg C, Baadsgaard O, et al. Interleukin-1 in human skin: dysregulation in psoriasis. J Invest Dermatol 1990;95: 24S-26S.

34. Gruaz D, Didierjean L, Grassi J, et al. Interleukin 1 alpha and beta in psoriatic skin: enzymoimmunoassay, immunoblot studies and effect of systemic retinoids. Dermatologica 1989;179:202-206.

35. Mee JB, Antonopoulos C, Poole S, et al. Counter-regulation of interleukin-1alpha (IL-1alpha) and IL-1 receptor antagonist in murine keratinocytes. J Invest Dermatol 2005;124:1267-1274.

36. Mee JB, Cork MJ, di Giovine FS, et al. Interleukin-1: a key inflammatory mediator in psoriasis? Cytokine 2006;33:72-78.

37. Prens EP, Benne K, van Damme J, et al. Interleukin-1 and interleukin-6 in psoriasis. J Invest Dermatol 1990;95:121S-124S.

38. Creamer $D$, Allen $M$, Jaggar $R$, et al. Mediation of systemic vascular hyperpermeability in severe psoriasis by circulating vascular endothelial growth factor. Arch Dermatol 2002;138:791-796.

39. Detmar M, Brown LF, Claffey KP, et al. Overexpression of vascula permeability factor/vascular endothelial growth factor and its receptors in psoriasis. J Exp Med 1994;180:1141-1146.

40. Heidenreich R, Rocken M, Ghoreschi K. Angiogenesis drives psoriasis pathogenesis. Int J Exp Pathol 2009;90:232-248.

41. Albanesi C, Scarponi C, Sebastiani S, et al. A cytokine-to-chemokine axis between $T$ lymphocytes and keratinocytes can favor Th1 cell accumulation in chronic inflammatory skin diseases. J Leukoc Biol 2001;70:617-623.

42. Giustizieri ML, Mascia F, Frezzolini A, et al. Keratinocytes from patients with atopic dermatitis and psoriasis show a distinct chemokine production profile in response to T cell-derived cytokines. J Allergy Clin Immunol 2001;107:871-877.

43. Griffiths $C E$, Voorhees JJ, Nickoloff BJ. Gamma interferon induces different keratinocyte cellular patterns of expression of HLA-DR and DQ and intercellular adhesion molecule-I (ICAM-I) antigens. $\mathrm{Br} J$ Dermatol 1989:120:1-8.

44. Nickoloff BJ, Lewinsohn DM, Butcher EC, et al. Recombinant gamma interferon increases the binding of peripheral blood mononuclear leukocytes and a Leu-3+ T lymphocyte clone to cultured keratinocytes and to a malignant cutaneous squamous carcinoma cell line that is blocked by antibody against the LFA-1 molecule. J Invest Dermatol 1988;90:17-22.

45. Simonart $\mathrm{T}$, Heenen $\mathrm{M}$. $\mathrm{T}$ cell/keratinocyte interactions in psoriasis: where is the trigger? Br J Dermatol 2007;156:171-172.

46. Chong BF, Wong HK. Immunobiologics in the treatment of psoriasis. Clin Immunol 2007;123:129-138

47. Cooper KD, Hammerberg C, Baadsgaard O, et al. IL-1 activity is reduced in psoriatic skin. Decreased IL-1 alpha and increased nonfunctional IL-1 beta. J Immunol 1990;144:4593-4603.

48. Debets R, Hegmans JP, Croughs P, et al. The IL-1 system in psoriatic skin: IL-1 antagonist sphere of influence in lesional psoriatic epidermis. J Immunol 1997;158:2955-2963.

49. Hammerberg C, Arend WP, Fisher GJ, et al. Interleukin-1 receptor antagonist in normal and psoriatic epidermis. J Clin Invest 1992;90: 571-583.

50. Hammerberg C, Bata-Csorgo Z, Voorhees JJ, et al. IL-1 and IL-1 receptor antagonist regulation during keratinocyte cell cycle and differentiation in normal and psoriatic epidermis. Arch Dermatol Res 1998:290:367-374.

51. Krueger JG. The immunologic basis for the treatment of psoriasis with new biologic agents. J Am Acad Dermatol 2002;46:1-23;quiz 23-26.

52. Kirschner N, Poetzl C, von den Driesch $\mathrm{P}$, et al. Alteration of tight junction proteins is an early event in psoriasis: putative involvement of proinflammatory cytokines. Am J Pathol 2009;175:1095-1106.

53. Dustin ML, Singer KH, Tuck DT, et al. Adhesion of T lymphoblasts to epidermal keratinocytes is regulated by interferon gamma and is 
mediated by intercellular adhesion molecule 1 (ICAM-1). J Exp Med 1988;167:1323-1340.

54. Plant $\mathrm{D}$, Young HS, Watson RE, et al. The CX3CL1-CX3CR1 system and psoriasis. Exp Dermatol 2006;15:900-903.

55. Raychaudhuri SP, Jiang WY, Farber EM. Cellular localization of fractalkine at sites of inflammation: antigen-presenting cells in psoriasis express high levels of fractalkine. $\mathrm{Br} J$ Dermatol 2001;144: 1105-1113.

56. Sugaya $M$, Nakamura $K$, Mitsui $H$, et al. Human keratinocytes express fractalkine/CX3CL1. J Dermatol Sci 2003;31:179-187.

57. Di Cesare A, Di Meglio P, Nestle FO. The IL-23/Th17 axis in the immunopathogenesis of psoriasis. J Invest Dermatol 2009;129: 1339-1350.

58. Piskin G, Sylva-Steenland RM, Bos JD, et al. In vitro and in situ expression of IL-23 by keratinocytes in healthy skin and psoriasis lesions: enhanced expression in psoriatic skin. J Immunol 2006;176: 1908-1915.

59. Eyerich S, Eyerich K, Pennino D, et al. Th22 cells represent a distinct human $\mathrm{T}$ cell subset involved in epidermal immunity and remodeling. J Clin Invest 2009;119:3573-3585.

60. Kagami S, Rizzo HL, Lee JJ, et al. Circulating Th17, Th22, and Th1 cells are increased in psoriasis. J Invest Dermatol 2010;130:1373-1383.

61. Lin AM, Rubin CJ, Khandpur R, et al. Mast cells and neutrophils release IL-17 through extracellular trap formation in psoriasis. J Immunol 2011; 187:490-500.

62. Detmar M, Yeo KT, Nagy JA, et al. Keratinocyte-derived vascular permeability factor (vascular endothelial growth factor) is a potent mitogen for dermal microvascular endothelial cells. J Invest Dermatol 1995;105:44-50. 